\title{
Impact of personal qualities and management skills of entrepreneurs on venture performance in Malaysia: opportunity recognition skills as a mediating factor
}

\begin{abstract}
This research studied the role of personal qualities, management skills, and opportunity recognition skills of entrepreneurs in influencing the venture performance. In this research, personal qualities and management skills were combined into a single construct, qualitiesskills. Specifically, this research explored and argued the role of opportunity recognition skills as a mediator between qualities-skills and three measures of venture performance. Additionally, the research addressed the specific components of opportunity recognition skills that had the mediating effect. The study was carried out in Malaysia, a fast developing country in South-East Asia. A questionnaire was designed and sent to 1275 small and medium enterprises (SMEs). The results indicated the following: (1) opportunity recognition skills acted as a ñpureò mediator, (2) opportunity recognition skills influenced the venture performance, (3) alertness mediated the relationship between personal qualities and venture performance, and (4) alertness and prior knowledge mediated the relationship between management skills and venture performance. Sales volume, sales growth, and stability in profit were used as measures of venture performance.
\end{abstract}

Keyword: Personal qualities; Management skills; Opportunity recognition skills; Venture performance; Malaysia 